Article

\title{
Design for Disruption: Creating Anti-Fragile Urban Delta Landscapes
}

\author{
Rob Roggema ${ }^{1,2}$ \\ ${ }^{1}$ Office for Adaptive Planning and Design, Cittaideale, 6707 LC Wageningen, The Netherlands; E-Mail: rob@cittaideale.eu \\ 2 Knowledge Centre NoorderRuimte, Hanze University Groningen, 9747 AS Groningen, The Netherlands
}

Submitted: 9 March 2018 | Accepted: 29 August 2018 | Published: 21 February 2019

\begin{abstract}
In this article three different responses are taken as the starting point how different types of disruption could be dealt with. These responses - repair, bounce back and grow stronger - are combined with three disruptions (sea level rise, storm surge and heavy rainfall), and then tested in three case studies. The result of the investigation is that anti-fragility (grow stronger) is a preferential approach to create delta landscapes that become stronger under influence of a disruption. Anti-fragility is for this research subdivided in three main characteristics, abundance of networks, adaptivity and counterintuitivity, which are used to analyse the three case study propositions. The type of response, type of disruption, characteristic of anti-fragility and the qualities of the case study area itself determine the design proposition and the outcome. In all cases this approach has led to a stronger and safer landscape. The concept of anti-fragility impacts on the period before a disruption, during and also after the disruptive impact. This gives it a better point of departure in dealing with uncertain or unprecedented hazards and disruptions.
\end{abstract}

\section{Keywords}

anti-fragility; delta landscape; disruption; intervention; coast; resilience

Issue

This article is part of the issue "The City of Flows: Urban Planning of Environmental Flows", edited by Rob Roggema (Cittaideale, The Netherlands/Hanze University Groningen, The Netherlands).

(C) 2019 by the author; licensee Cogitatio (Lisbon, Portugal). This article is licensed under a Creative Commons Attribution 4.0 International License (CC BY).

\section{Introduction}

Though many areas suffer from the impact of climate change, deltas and coasts are seen as belonging to the most vulnerable areas in the world (Balica, Wright, \& Van der Meulen, 2012; Climate Institute, n.d.; Meijer \& Nijhuis, 2014). These areas are at risk of climate impacts such as sea level rise, storm surges and cyclones, and they also are the areas with largest population concentrations and economic prosperity, which places these areas at an increased vulnerability level. When a disruption occurs in deltas and coasts several responses are used to recover: repair, bounce back or grow stronger.

\subsection{Repair}

The dominant response is repairing damage after the disruption and rebuild the city. In this option defensive structures such as dams, seawalls are built, aiming to pro- tect as many assets in the urban landscape by excluding disruption. Barriers are raised to keep the external impact away from the city. However, this equilibrium is setup for disaster. Eventually, even the strongest protective system is not strong enough to withstand unprecedented impacts, hence future disruptions will require rebuilding again. Good examples of this approach are the Dutch Deltaworks (Rietveld, Rietveld, \& Habets, 2017) and the Thames Barrier (Kendrick, 1988), but also the Rebuild by Design (Ovink \& Boeijenga, 2018) after hurricane Sandy hit New York belongs in a way to this category, though rebuilding in New York takes place by creating more resilient and soft defensive structures.

\subsection{Bounce Back}

The second approach to deal with disruption is to design a city that can keep performing its basic functions (e.g., ecological resilience; Gunderson \& Holling, 2002) 
and bounces back (e.g., 'engineered' resilience; O'Hare $\&$ White, 2013). The concept of resilience is used to describe how cities and regions could embed security and risk management features into their built environment and governance systems as part of a broader drive towards more safe and sustainable communities (Coaffee \& Bosher, 2008). Measures are taken both to resist disruption as to recover rapidly afterwards (Coaffee, 2008). Resilience shows similarities to relational understanding of spatiality (Massey, 2005) as both put emphasis on fluidity, reflexivity, contingency, connectivity, multiplicity and poly-vocality (Davoudi \& Strange, 2009). Place is seen as complex interconnected socio-spatial systems with unpredictable feedback processes at multiple scales and timeframes (Davoudi, 2012). A more resilient urban environment for instance planned under an interpretive regime reducing the 'will to order', discourages fixity and rigidity (Davoudi, 2011).

\subsection{Grow Stronger}

The third response is less used. The concept of antifragility (Taleb, 2012), a theory focusing on how systems can become stronger under stress, could be beneficial for deltas confronted with disruptions. This concept will be further explored how it can be of use in spatial design in this article.

Each of these responses have their (dis)advantages, depending on the type of disruption and the context in which it takes place. In this article the problem will be defined first. Following this, three types of potentially disruptive developments for deltas will be described. In Section 4 the concept of anti-fragility is further elaborated on and three key characteristics, networks, adaptivity and counterintuitivity, are defined. These characteristics are then used to test the impact of three disruptions in three case studies and investigate whether they can grow anti-fragility in spatial planning. The article ends with drawing conclusions and formulate several recommendations.

\section{Problem Statement}

The sustainable urban development model is under threat of a range of developments of economic, social, environmental and spatial nature (European Union, 2011, pp. vi), terrorism (Marcuse, 2006; Rossi-Hansberg, 2004) and climate change (Carter et al., 2015; De Sherbinin, Schiller, \& Pulsipher, 2007; Hallegatte, Green, Nicholls, \& Corfee-Morlot, 2013). While it is common to see disasters as 'causes', and the destruction of the built environment as 'effects', the intricate links between cities and disasters cannot be described by a unidirectional cause-and-effect relationship. The city-disasters nexus is a bidirectional relationship, which constantly shapes and is shaped by other processes, such as climate change (Wamsler \& Brink, 2016). The majority of current responses applied in cities focus on protection, safety and security, or disaster risk reduction (DRR). This leads to a controlled but narrow equilibrium. If developments work out a little different than projected, a protective approach will not suffice, as city influences the disaster as much as the other way around and this will 'undermine' the well-meant protection which only prevents one direction: the impact of the disaster on the city. Instead of being the victim of external factors, the city should enhance its holistic capacity to not only deal with multiple and different complexities resulting from external disruptions, but also minimise its influence on the genesis of disasters. Additionally, it would be even more interesting if the quality, safety, prosperity and beauty of deltas improves when a disruption occurs. This bidirectional relationship of decreasing negative impact of disruptions and at the same time increasing the strength and quality of the delta requires urban design solutions, which can turn threats into benefits. Design-led research (Roggema, 2016) can provide insights how to use the power a disruption brings to make deltas stronger. The goal therefore is to find mechanisms that increase the quality of urbanised deltas as result of the disruption.

\section{Disruptive Developments in Deltas}

In general, delta areas are under threat of three main potentially disruptive impacts: sea level rise, storm surges and heavy rainfall during storms, cyclones or hurricanes.

\subsection{Sea Level Rise}

Due to a complex of factors sea level is rising and will continue to rise in an accelerated fashion (Kopp et al., 2016; Nerem et al., 2018; Vermeer \& Rahmstorf, 2009; Walsh et al., 2014, p. 45). Due to sea level rise coastal zones are under threat of inundation and flooding. One of the most recent integral predictions for change in global sea level estimates that in a worst-case scenario the level will increase with $2.5 \mathrm{~m}$ by the end of the century (NOAA, 2017) or as much as 3-3.5m for most of the United States (Climate Central, 2017). The vulnerability of deltas and coastal zones for sea level rise is the elevation: it is obvious that lower lying land is more vulnerable for sea level rise than higher elevations.

\subsection{Storm Surges}

Add significant extra risks, leading to higher costs and large spatial impact on land use (Neumann et al., 2015). For several hurricanes in the United States the surge has been estimated and ranges between almost $10 \mathrm{~m}$ (Katrina), to $7 \mathrm{~m}$ (Ike) and 2-4m for Charley and Irene (Weather.Gov, n.d.). In Norway, calculations show that a storm surge triples or multiply fivefold sea level rise (Norwegian Directorate for Civil Protection, 2017). These examples illustrate that different contexts imply other additional water levels attacking the coast. It is clear that centimetres of sea level rise often lead to meters of surge. 
The vulnerability of deltas and coast is in this case the level at which coastal protection can take away wave and surge energy.

\subsection{Heavy Rainfall}

Tropical cyclones or hurricanes, when they make landfall, come along with torrential rain and contribute for more than $50 \%$ to extreme precipitation events both with regards to Atlantic tropical cyclones (Aryal, Villarini, Zhang, \& Vecchi, 2018) as the Indian Ocean cases (Lang, 2018). Hopkins and Holland (1997) found similar results for East Coast Australia, and Taiwan (Chen, Tan, \& Shih, 2013). The vulnerability of deltas and coast for heavy rainfall is determined by the spatial capacity in landscapes and cities to temporarily store large amounts of water. Often this capacity is far below the required space causing flooding.

In Section 5, these disruptions will be used to investigate whether the three case studies could grow stronger by using anti-fragile spatial interventions.

\section{Anti-Fragility}

Systems vary in their ability to deal with stress, ranging from being fragile and degrading under stress, be robust and remain unchanged during stress, or to be anti-fragile and improve while suffering stress (Johnson \& Gheorghe, 2013). A fragile object is an object, which perturbations can only harm, damage or break. Something is robust if events, perturbations, volatility, disorder cannot harm it. At the same time, nothing can benefit from it. Resilience is the capacity of a system, to absorb a shock without breaking, perhaps deforming but then rebounding to its previous condition. Therefore, in the case of resilience as well as robustness, time ultimately leaves the object or the system unchanged (Blečić \& Cecchini, 2017). Anti-fragility is beyond resilience or robustness. The resilient system resists shocks and stays the same; the antifragile benefits from shocks, thrive and grow when exposed to volatility, randomness, disorder and stressors, and it loves adventure, risk, and uncertainty (Taleb, 2012, pp. 21-22). An anti-fragile system creates opportunities to learn from small mistakes, trial-end-error, to deal with new challenges, to improve and innovate. Anti-fragility means that mistakes have reversible consequences and we can learn from them. In this situation there are more upside than downside effects from random events (nonlinear gains), as losses from mistakes are small, while a positive option may appear that supports development (Platje, 2015).

In order to find general criteria for an anti-fragile development, the opposite of the criteria defined for fragile planning (Blečić \& Cecchini, 2017, p. 6) is combined with anti-fragile criteria (Johnson \& Gheorghe, 2013):

- A global idea for future direction that must be clear and operates as a general guideline, stimulate novelty and allow for disorder;
- Self-organising elements at the local scale towards that general direction;

- Redundancy through creating space that is not allocated for any specific use, e.g., absorption zones;

- Only few guiding rules for order in place, stimulate tipping points to emerge;

- Multi-functionality, simultaneity and mixed uses, for a selected and limited number of system states, e.g., certain mixes of use;

- Environments that allow for surprise and counterintuitive feedback;

- Equally divided resources over the area;

- Similar spatial qualities everywhere.

These criteria can be interpreted and combined with each other to formulate three conditions for antifragility to emerge: an abundance of networks (Roggema \& Stremke, 2012), high level of adaptivity (Roggema, 2012a; Roggema \& Van den Dobbelsteen, 2012) and application of counterintuitive design principles (Roggema, in press). Each of these contain their own set of elements and properties that could support deltas and coasts in dealing with disruptions.

\subsection{Abundance of Networks}

If a system contains more intense networks of water, energy, mobility, communication, social, trade, etc., this implies there will be more connections, more hubs and nodes, hence higher connectivity. This makes the system very flexible and adaptive, as for every connection several alternatives are in operation and can be used whenever needed. A fine network also guarantees that resources and spatial quality can be spread evenly over the system; there is no core that has preferential access or rights. At the same time the nodes that are connected with most other nodes is the place where gravity moves towards: more people, more movement, more exchange and higher values will be realised in these places. When the network is fine, this implies multi-functionality and mixed land use, as on a relatively small area highly connected and less connected nodes exist next to each other and give reason for busy and quiet connections, and differences in land-use. Under threat of disruptions such rich networks can grow in functionality, for instance when connections can take up roles they didn't have before (new transport routes when others are flooded, and squares becoming water storage or roads waterways).

\subsection{Adaptivity}

An adaptive landscape is one that has the spatial and functional options to change whenever necessary. The transformation of places from a certain use to another, or spaces that are made redundant in order to accommodate sudden needs, such as for capturing and store water, increase the possibility to adjust to new and unprecedented impacts. The general direction for the future is 
established and should be supported by the residents of the area, but this general direction contains the freedom and flexibility to realise different future spatial constellations, which is ben built up from its smaller spatial elements. The space is created for self-organisation as to find the right mix of functions and spaces required at every given moment. Some functions emerge, while others diminish, and spaces constantly transform. Disruptions will enforce these transformations and changes to adjust according the demands posed by the type of disruption. For instance, accelerated sea level rise would require the use of absorption zones where the rising water can find its space as to increase the safety levels. In the design of these coastal zones the inclusion of spatial redundancy needs to provide these zones.

\subsection{Counterintuitivity}

Counterintuitive solutions are necessary to counteract unprecedented disruptions. If these novel disruptions are treated with the same solutions as former problems were solved, it is almost certain they will not suffice to prevent the new disruption from impacting the land. Therefore, the design process should be organised in a way it gives space to think outside the box and invent new propositions that are different from the business as usual policies that have been used in the past. These counterintuitive solutions can stimulate emergence of unexpected developments, tipping points that turn spatial configuration around in order to create the space for self-organised transformations that make the landscape stronger than before. This way the disruption becomes the initiator of a new, stronger, landscape. For instance, if storm surges threaten the coast the business as usual solution would be to strengthen and heighten the seawall. However, this solution would only increase the risk, as future storm surges could be more severe than expected and cause a disaster. A counterintuitive solution could be to allow seawater in the hinterland from the beginning as to bypass the risk and create a stronger, more beautiful landscape with the seawater as an integral part of it.

\section{Case Studies}

In this article three case studies are taken to illustrate the mechanisms how the quality, strength and/or safety of delta landscapes can be increased. In every case study one major possible disruption is taken as the entrance point for the design propositions. Subsequently it will be described how the delta landscape could become stronger as result of the disruption. Therefore, the three main characteristics of anti-fragility are used to analyse the qualities of the design propositions. Finally, for each case study it will be discussed whether the spatial propositions could be beneficial beyond the major disruption defined at the beginning. Each of the case studies, Double Defence (Roggema, Van den Dobbelsteen,
\& Stegenga, 2006), the Sydney Barrier Reef (Roggema, 2017) and the Floodable Eemsdelta (Roggema, 2012b), is used to retrospectively illustrate the potential of antifragility avant-la-lettre.

\subsection{Double Defence}

The Double Defence project (see Figure 1) is located in the northern part of the Netherlands. The north shores and the Wadden Sea are currently under threat of sea level rise and storm surges. This area is very vulnerable because it is low lying and the high ecological values of its tidal flats, which, under accelerated sea level rise, might drown. Storm surges could attack the coastal protection, which has, compared to other parts of the Netherlands, a lower safety level.

The proposed response to these potential disruptions is to introduce a second row of barrier islands in front of the existing ones. Because of the new islands a storm surge is not only prevented from harming the coastline, which is miles further away, it also adds a huge amount of extra sediment, such as clay and sand particles to the area behind and in between the existing and new islands. Because the islands create a more tranquil maritime environment, these particles get the chance to sink down and build up existing or new sandbanks. This enhances the wetland ecosystem of the Wadden Sea, not only in quantity but also in quality. Instead the existing islands and sandbanks are threatened of washing away during a storm surge, the new islands provide the incentive for more and new ecological area to emerge.

The introduction of an extra row barrier islands starts a new development of land-genesis. The main, longterm objective is clear, whilst the specific shape of the wetlands is dependent on the interaction of the storm surge, amount of sediment, existing sandbanks and wave strength and direction. The shape of the New Wadden will emerge under influence of the currents and available sediments, and constantly change shape. This adaptivity is possible because the area is effectively an extensive absorption zone where water, wind and sand self-organise the build-up of new sandbanks, and use the redundant space as needed. The introduction of the new islands is counterintuitive. The regular solution in this case would be to protect the existing islands by strengthening the beach and dune systems or add sand in the system to feed the build-up of sandbanks. The result of the antifragile proposition is that a rich nature emerges, which by its land-forming increases the safety of the entire northern part of the Netherlands.

On the new islands, opportunities for new uses, such as recreation, urban living, agriculture and renewable energy generation arise. At the same time, the existing hinterland, due to its better protection, could explore new developments and become a place for food supply, urban living, water retention and high-tech industrial activities, which would be under serious scrutiny if the design intervention would not be effectuated. 


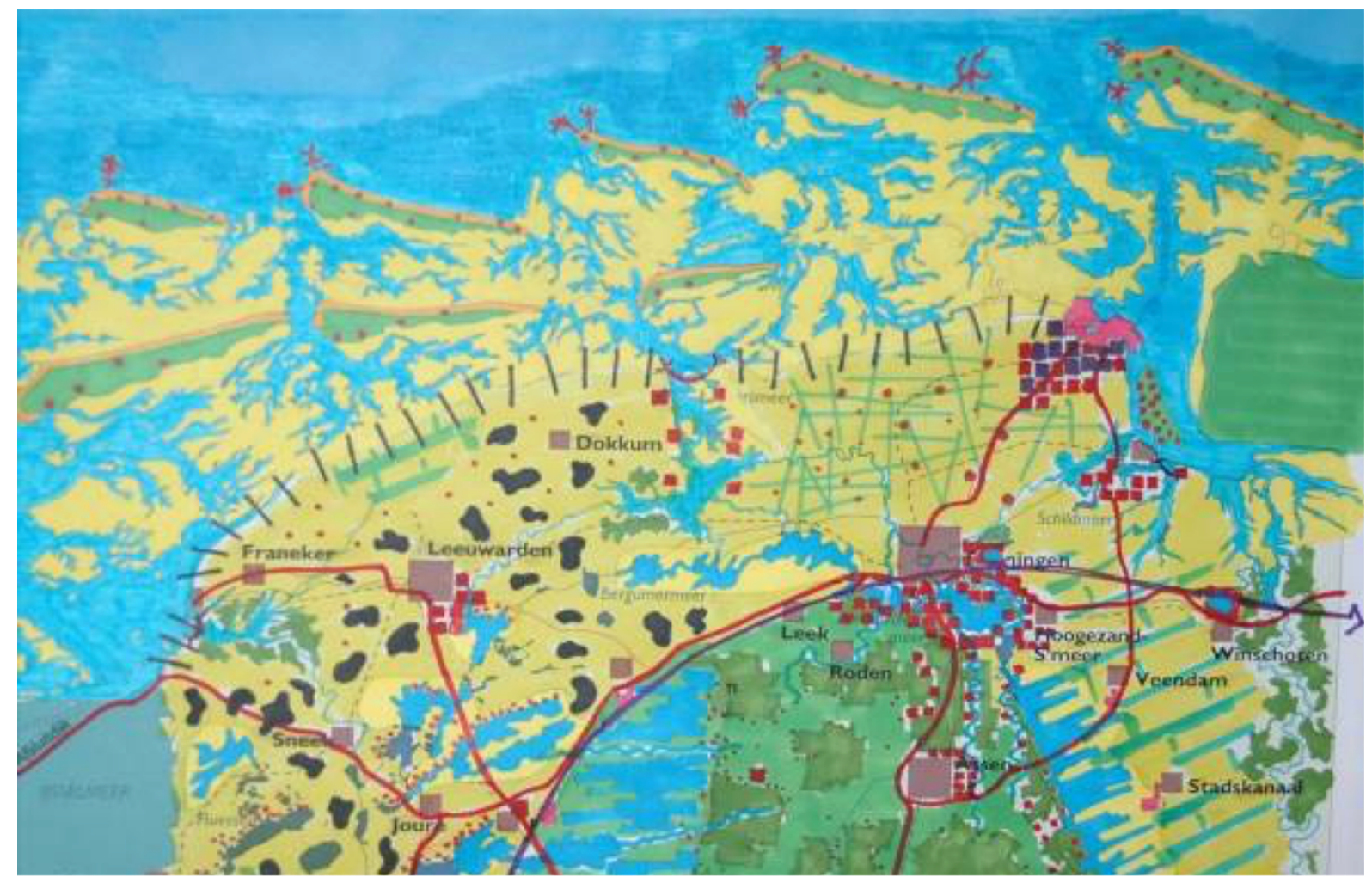

Figure 1. Plan for Double Defence (Roggema et al., 2006).

Double Defence is a project that deals predominantly with storm surges, uses adaptability and counterintuitivity to develop a proposition that strengthens the delta landscape.

\subsection{Sydney Barrier Reef}

The Sydney Barrier Reef (see Figure 2) is a proposition for the coastal zone of Eastern Australia, between Newcastle and Wollongong. The current situation is not suitable for reef development but in the future that will change, as temperatures in the southern Pacific will rise and eventually create a suitable environment for a barrier reef. Accompanying higher temperatures moving south is the emergence of cyclones moving further away from the equator (Sharmila \& Walsh, 2018). These cyclones, similar to recent ones hitting Queensland, will impact the New South Wales (NSW) coastline in the future. The main disruption in the Sydney region is therefore the rise in temperatures of the ocean, as this will cause cyclones to move further south and cause storm surges, severe wind and rainfall. At the same time the Great Barrier Reef (GBR) in the northern parts of the southern Pacific will warm up and this causes bleaching of the reef. In recent years up to $50 \%$ of the GBR has suffered from this process, and it is expected that with further rise in temperatures the acidity of the ocean will increase, and the reef will come under further pressure.

The proposition to deal with several of these problems at the same time is to create the conditions in front Sydney's coast for the development of a barrier reef. A natural reef can grow on artificial materials such as shipwrecks or abandoned oilrigs, turning the problematic abandoned rigs into an advantage. The future Sydney Barrier Reef protects the coast against the impact of storm surges accompanying cyclones but forms also a refuge for the GBR. The first tropical fish and coral have been spotted in front of the Sydney coast (Booth \& Sear, 2018), which makes it opportune to provide the right habitat for more of these species.

The introduction of the artificial elements that form the basis for tropical reef development is counterintuitive, as the normal response to more intense storms would be to replenish the beaches, and try to strengthen the coastal protection structures, while at the same time all efforts would be put to rescuing the GBR. Accepting the new normal and invent a solution that could solve multiple problems at once gives the NSW-coast a high level of adaptivity. The design of the underwater landscape is detailed in a way it will protect the coast, but also allow for emergent developments, such as higher sea levels, more or less sediments and other coastal dynamics, should they occur. The few driving forces of this coastal system, such as the distance from the coast, the gaps in between parts of the reef and the exact positioning of the sunken materials, determine the spatial reorientation of this redundant absorption zone. Once the artificial basis is created the growth of natural reef takes place in a self-organising way. This way the global direction for the NSW-coast is understood, but at the same time the freedom to deal with change and uncertainty will allow the system to develop in a fitting way. 

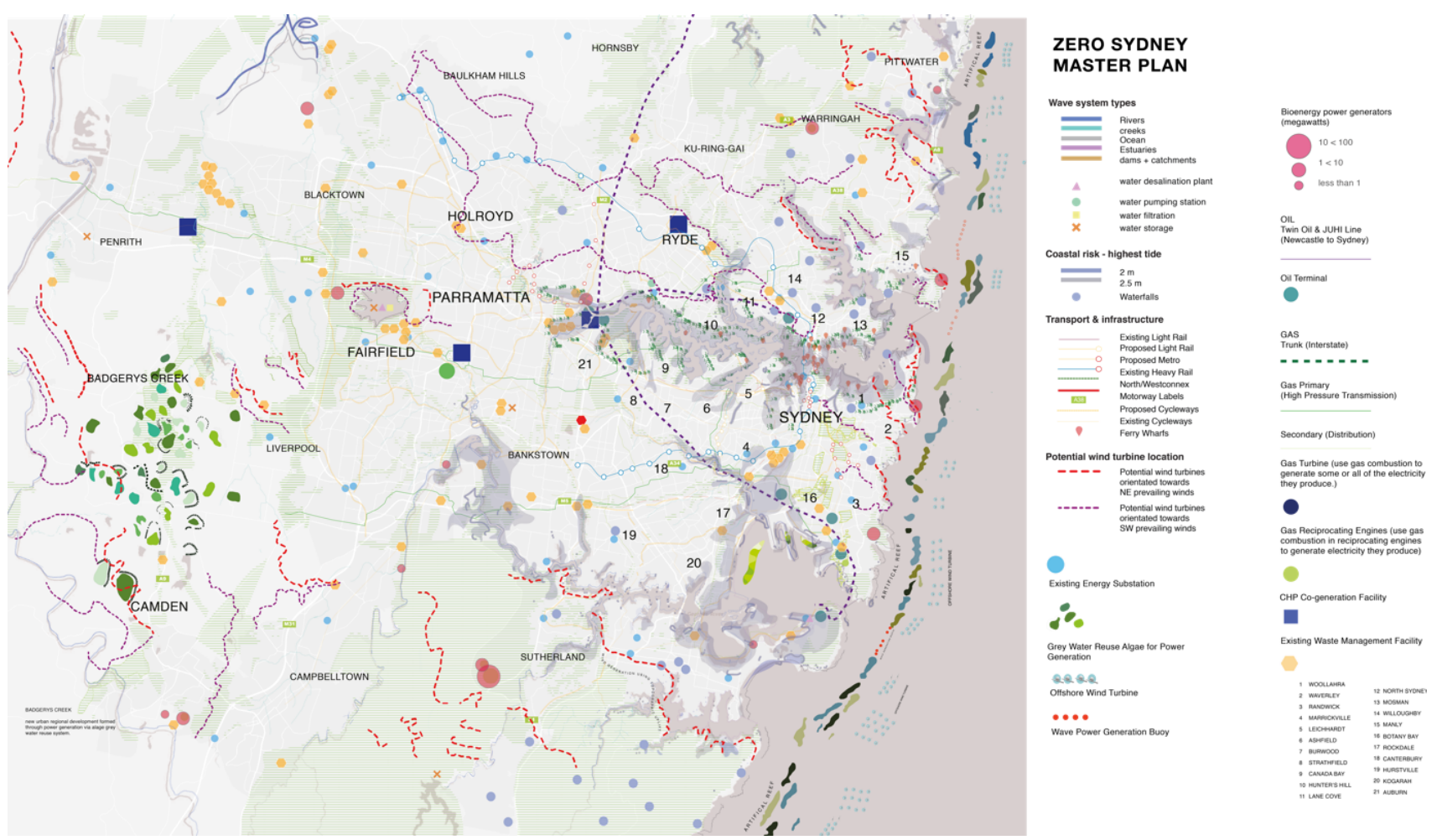

Figure 2. Sydney Barrier Reef (Roggema, 2017).

The introduction of a Sydney Barrier Reef implies several other advantages. In normal weather the gaps in between the reef parts form little tunnels hence will amplify the surge and cause better surfing conditions at the coast. These gaps are therefore designed in a way they exactly will have the most impact at the most popular surf beaches. In between these gaps wave power 'plants' are proposed, which will emerge from the sea when stronger storm surges occur. This way renewable energy is generated and at the same time the reef is 'closed off' so it increases safety levels. An additional benefit from sinking shipwrecks and oilrigs is they are excellent dive sites. Together with the colourful reef itself these sites are very attractive for tourism.

The proposition of the Sydney Barrier Reef predominantly deals with the impacts of storm surges through cyclones and, to a lesser extent, sea level rise. The main disruption is the rise in temperature which is used as an opportunity in this project. It allows for a counterintuitive and adaptive solution.

\subsection{Floodable Eemsdelta}

The Eemsdelta region is located in the northeast of the Netherlands. It is a historically valuable area where until 1000AC people used to live on artificial hills, created by piling up their own waste, amidst a tidal flat. Once the residents started diking the land a coherent system of coastal protection emerged up to the point they started to make their own land and reclaimed this from the sea by introducing a wooden structure system in the sea that was capable of capturing sediment and this way grew above sea levels and became new land. This region is now under threat of accelerated sea level rise and occasional storm surges.

The proposed intervention in this landscape is to create consciously a hole in the coastal protection system. This way, a Floodable Eemsdelta (see Figure 3) will emerge over time. The water will enter the hinterland and fill up the landscape as high as the sea level will rise. This implies a twofold mechanism. The first element is that it doesn't matter how fast sea level rise happens. At every stage of a sea level rise the landscape is ready and used to the water in the local environment. Secondly, an eventual disaster, e.g., a dike breech, will not happen due to the hole that has been there forever. This way people in the Eemsdelta region can predict the future circumstances they will live in. As a matter of fact, the water increases the quality of living in the area, and provides an abundant resource for cooling, against drought and other uses. A second intervention optimally profits from the seawater. Applying the historic system of land reclamation, also in this landscape wooden structures are proposed that will capture sand and clay sediments hence grow the ground level of the landscape. Once the wooden structures are in place, poles and to them floating houses can be attached. This way the houses are prepared for coming seawater, they won't float away, and the residents are certain of the most beautiful (and safe) landscape to live in.

In normal situations sea level rise will be dealt with by increasing the protective seawall and increase its height and strength. To purposely make a gap in the dike is, especially in the Netherlands, counterintuitive. Using a sim- 


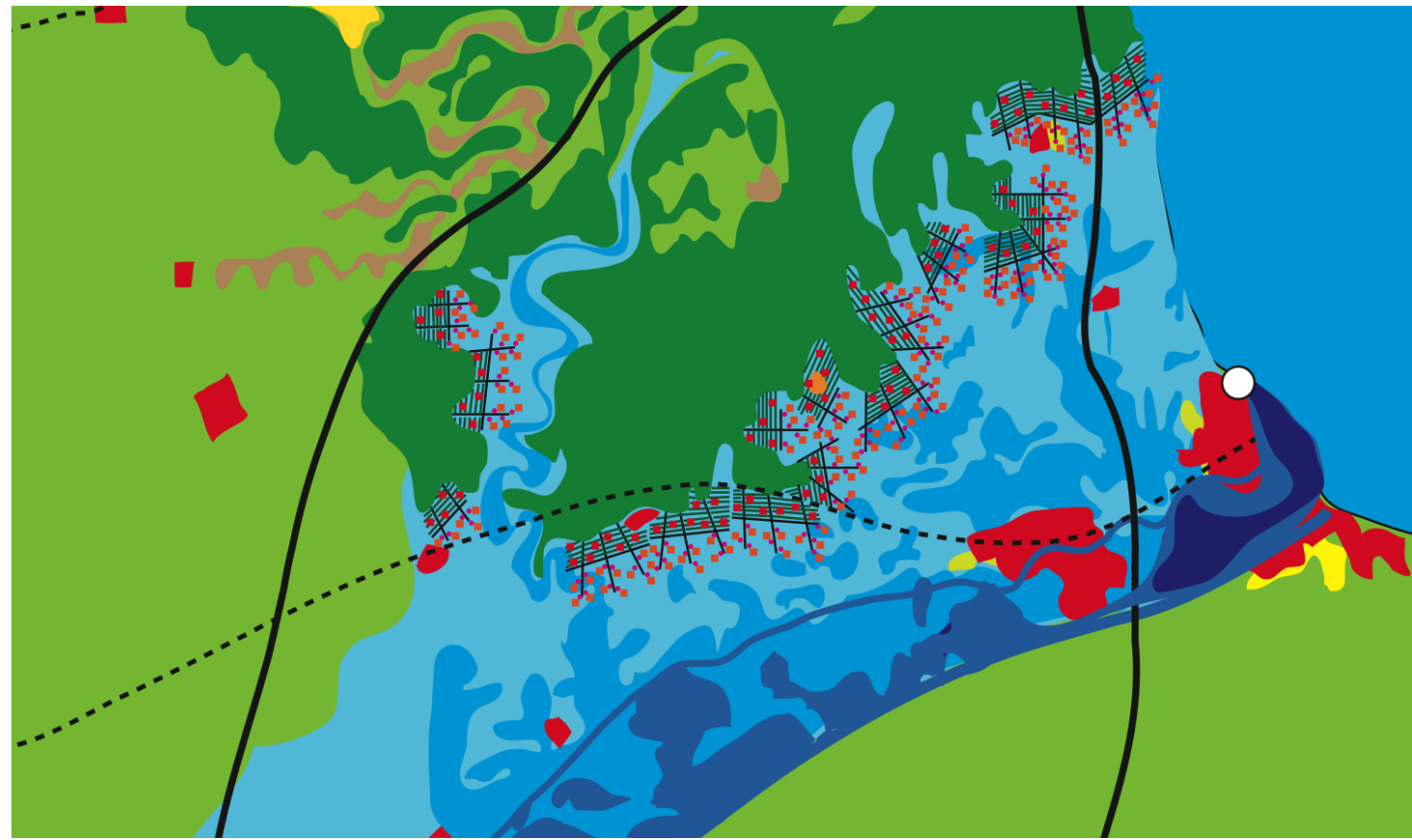

Figure 3. Floodable Eemsdelta (Roggema \& Van den Dobbelsteen, 2012).

ilar principle as applied in the Sand Engine (Stive et al., 2013), the incoming water enforces the landscape behind the dike to adjust and adapt. This delta landscape self-organises its components to make sure the typology of housing and their location is chosen in safe places. Because the water will flow to the lowest point, after the inlet the main direction of how the landscape will evolve is clear. In detail natural processes such as wind speed and direction, the amount and type of sediment, the shape of contour lines are the few guiding principles that determine the exact land forming, the build-up of new soil and where new housing can be developed. The entire zone under influence of the water is redundant and functions as an absorption zone, in which many different developments can be accommodated. The pace of sea level rise is not relevant, as the area is always prepared for any change in sea level.

Besides accommodating sea level rise in a secure way, this proposition also creates the absorption zone for collecting and storing seawater during and after a storm surge, as well as the impact of heavy rainfall in the landscape itself.

The Floodable Eemsdelta project predominantly focuses on disruptive sea level rise and to a lesser extent storm surges and heavy rainfall, using an unorthodox and counterintuitive approach in which an entire landscape provides the space to adapt to constantly changing circumstances.

\section{Conclusions}

In this article three possible responses to disruptions in delta landscapes are identified: repair, bounce back and grow stronger. The latter one is the most interesting, though less researched one. If a system can improve its quality and gets stronger this is called anti-fragility. In this article it is illustrated that delta landscapes, under threat of multiple possible disruptions, such as sea level rise, storm surges or heavy rainfall, all benefit from using the anti-fragility concept as design approach. Each of the case studies show an increase in quality and strength if antifragile characteristics, such as adaptivity, counterintuitivity and, in these case studies to a lesser extent, abundant networks are used in the design propositions. The Double Defence project enhances the size and quality of the natural wetlands of the Wadden Sea, at the same time increasing the safety level of the coast. The Sydney Barrier Reef increases the protection of the coast and simultaneously creates new tropical habitat for fish and coral. Moreover, it forms a refuge for the threatened species of the GBR. The Floodable Eemsdelta increases the quality of the living environment once the seawater enters the hinterland, at the same time bypassing the threat of a dike breaking through.

As illustrated in the case studies the characteristics of anti-fragility not only help these delta and coastal landscapes to bounce back after a disruption, they use the disruptive impacts as a mean to improve and grow. Because anti-fragility makes systems stronger under stress it is seen as a concept that goes beyond resilience, which aims to keep the system functioning during a disruption. In this sense designing an anti-fragile delta firstly anticipates the disruption, secondly it creates a stronger environment during the disruption, so the landscape can keep its basic functions, and thirdly design in an antifragile way results in higher qualities in the area afterwards. Anti-fragility is therefore having effect before, during and after a disruption, while resilience is mainly active during 
the disruption and the robust approach aims to prevent a disruption before it happens.

The notice that an anti-fragile system gets stronger under stress is appealing. Anti-fragility is used in several disciplines, such as IT, organisational theory and business, but the application in spatial design is novel. In this article three main drivers of an antifragile landscape are presented. A delta landscape becomes more stronger before, during and after a disruption if abundant networks and regenerative nodes are apparent, the adaptive capacity is large and counterintuitive ideas and concepts are used in the design. The case studies resemble a broad range of anti-fragile characteristics. Resorting under the main concepts of network abundance, adaptivity and counterintuitivity, detailed qualifications used to design an antifragile landscape are, amongst others: spatial redundancy in absorption zones, counterintuitive interventions, self-organisation, multiple uses and spaces, allow for disorder, few guiding rules, tipping points and novel solutions. These aspects are used in the design of the case studies, though not often made explicit.

Applying the concept of anti-fragility in delta and coastal landscapes supports these landscapes to constantly improve. The bidirectional relationship between cities (urbanised deltas) and disasters can be turned into a symbiotic relationship by using the antifragile concept. Instead of the urban landscape causing disruptions and then suffer from it, anti-fragility enhances the quality of the urban landscape by which the disruption will be less severe and uses the disruption subsequently to grow stronger. When urban landscapes increase the abundance of its networks, improve the adaptability and use counterintuitivity in the design process, the overall quality of the area will grow. This way urban and landscape designers have influence on establishing this symbiotic relationship by applying these principles in designs for delta landscapes.

In this article three different elements have been taken as the starting point for investigating the use of anti-fragility in landscape urbanism in deltas and coastal zones. The type of response (repair, bounce back and grow stronger) is combined with the type of disruption (sea level rise, storm surge and heavy rainfall) for three antifragile characteristics (abundance of networks, adaptivity and counterintuitivity), in three case studies (Double Defence, Sydney Barrier Reef and Floodable Eemsdelta). The typical constellation and combinatory of these elements determine the specific design task and the design propositions. This system of linking the type of response, disruption, antifragile characteristics and the area qualities could be used in every situation to propose design solutions that support the area to become safer and stronger.

\section{Conflict of Interests}

The author declares no conflict of interests.

\section{References}

Aryal, Y. N., Villarini, G., Zhang, W., \& Vecchi, G. A. (2018). Long term changes in flooding and heavy rainfall associated with North Atlantic tropical cyclones: Roles of the North Atlantic oscillation and El Niño-Southern oscillation. Journal of Hydrology, 559, 698-710. https://doi.org/10.1016/j.jhydrol.2018.02.072

Balica, S. F., Wright, N. G., \& Van der Meulen, F. (2012). A flood vulnerability index for coastal cities and its use in assessing climate change impacts. Nat Hazards, 64, 73-105. https://doi.org/10.1007/s11069012-0234-1

Blečić, I., \& Cecchini, A. (2017). On the anti-fragility of cities and of their buildings. City, Territory and Architecture, 4(3), 1-11. https://doi.org/10.1186/s40410016-0059-4

Booth, D. J., \& Sear, J. (2018). Coral expansion in Sydney and associated coral-reef fishes. Coral Reefs, Journal of the International Society for Reef Studies. Advance online publication. https://doi.org/10.1007/s00338018-1727-5

Carter, J. G., Cavan, G., Connelly, A., Guy, S., Handley, J., \& Kazmierczak, A. (2015). Climate change and the city: Building capacity for urban adaptation. Progress in Planning, 95, 1-66. https://doi.org/10.1016/ j.progress.2013.08.001

Chen, J.-M., Tan, P.-H., \& Shih, C.-F. (2013). Heavy rainfall induced by tropical cyclones across Northern Taiwan and associated intraseasonal oscillation modulation. American Meteorological Society, 26, 7992-8007. https://doi.org/10.1175/JCLI-D-12-00692.1

Climate Central. (2017). Extreme sea level rise and the stakes for America. Climate Central. Retrieved from www.climatecentral.org/news/extreme-sea-level-rise -stakes-for-america-21387

Climate Institute. (n.d.). A rising concern. Climate Institute. Retrieved from climate.org/sea-level-rise-riskand-resilience-in-coastal-cities

Coaffee, J. (2008). Risk, resilience and environmentally sustainable cities. Energy Policy, 36, 4633-4638.

Coaffee, J., \& Bosher, L. (2008). Integrating counterterrorist resilience into sustainability. Proceedings of the Institute of Civil Engineers: Urban Design and Planning, 161(2), 75-83.

Davoudi, S. (2011). The legacy of positivism and the emergence of interpretive tradition in spatial planning. Regional Studies. Advance online publication. http://dx.doi.org/10.1080/00343404.2011.618120

Davoudi, S. (2012). Resilience: A bridging concept or a dead end? Planning theory and Practice, 13(2), 299-333.

Davoudi, S., \& Strange, I. (2009). Space and place in the twentieth century planning: An analytical framework and an historical review. In S. Davoudi \& I. Strange (Eds.), Conceptions of space and place in strategic spatial planning (pp. 7-42). London: Routledge.

De Sherbinin, A., Schiller, A., \& Pulsipher, A. (2007). 
The vulnerability of global cities to climate hazards. Environment and Urbanization, 19(1), 39-64. https://doi.org/10.1177/0956247807076725

European Union. (2011). Cities of tomorrow. Challenges, visions, way forward. Brussels: European Commission, Directorate General for Regional Policy.

Gunderson, L. H., \& Holling, C. S. (Eds.). (2002). Panarchy: Understanding transformations in systems of humans and nature. Washington, DC: Island Press.

Hallegatte, S., Green, C., Nicholls, R. J., \& CorfeeMorlot, J. (2013). Future flood losses in major coastal cities. Nature Climate Change, 3, 802-806. https:// doi.org/10.1038/nclimate1979

Hopkins, L. C., \& Holland, G. J. (1997). Australian heavy-rain days and associated East Coast cyclones: 1958-1992. American Meteorological Society, 10, 621-635.

Johnson, J., \& Gheorghe, V. (2013). Anti-fragility analysis and measurement framework for systems of systems. International Journal of Disaster Risk Science, 4(4), 159-168. https://doi.org/10.1007/s13753-0130017-7

Kendrick, M. (1988). The Thames barrier. Landscape and Urban Planning, 16(1/2), 57-68. https://doi.org/ 10.1016/0169-2046(88)90034-5

Kopp, R. E., Kemp, A. C., Bittermann, K., Horton, B. P., Donnelly, J. P., Gehrels, W. R., . . . Rahmstorf, S. (2016). Temperature-driven global sea-level variability in the common era. Proceedings of the National Academy of Sciences of the United States of America, 13(11), E1434-E1441. https://doi.org/10.1073/ pnas.1517056113

Lang, S. (2018). NASA analyzes no. Indian Ocean rainfall of soaking separate cyclones. Phys. Retrieved from phys.org/news/2018-06-nasa-indian-ocean-rainfallcyclones.html\#jCp

Marcuse, P. (2006). Security or safety in cities? The threat of terrorism after 9/11. International Journal of Urban and Regional Research, 30, 919-929. https://doi.org/10.1111/j.1468-2427.2006.00700.x

Massey, D. (2005). For space. London: Sage.

Meijer, H., \& Nijhuis, S. (2014). Urbanised Deltas in transition. Rotterdam: nai010 Publishers.

Nerem, R. S., Beckley, B. D., Fasullo, J. T., Hamlington, B. D., Masters, D., \& Mitchum, G. T. (2018). Climatechange-driven accelerated sea-level rise detected in the altimeter era. Proceedings of the National Academy of Sciences of the United States of America, 115(9), 2022-2025. https://doi.org/10.1073/ pnas. 1717312115

Neumann, J. E., Emanuel, K., Ravela, S., Ludwig, L., Kirshen, P., Bosma, K., \& Martinich, J. (2015). Joint effects of storm surge and sea-level rise on US Coasts: New economic estimates of impacts, adaptation, and benefits of mitigation policy. Climatic Change, 129(1/2), 337-349.

NOAA. (2017). Global and regional sea level rise scenarios for the United States (NOAA Technical Report
NOS CO-OPS 083). Silver Spring, MD: US Department of Commerce. Retrieved from tidesandcurrents.noaa. gov/publications/techrpt83_Global_and_Regional_ SLR_Scenarios_for_the_US_final.pdf

Norwegian Directorate for Civil Protection. (2017). Integrating sea level rise and storm surges in local planning. Tønsberg: dsb.

O’Hare, P., \& White, I. (2013). Deconstructing resilience: Lessons from planning practice. Planning Practice and Research, 28(3), 275-279.

Ovink, H., \& Boeijenga, J. (2018). Too big. Rebuild by design: A transformative approach to climate change. Rotterdam: nai010 Publishers.

Platje, J. (2015). Sustainability and anti-fragility. Economic and Environmental Studies, 15(4), 469-477.

Rietveld, R., Rietveld, E., \& Habets, D. (2017), Dutch Delta works: From engineering feat to cultural statement. The Architectural Review. Retrieved from www. architectural-review.com/essays/dutch-delta-worksfrom-engineering-feat-to-cultural-statement/100200 89.article

Roggema, R. (in press). The joy of counterintuitive-ity. In E. Mossop (Ed.), Design for coastal resilience. Abingdon: Routledge.

Roggema, R. (2017). The Sydney barrier reef: Engineering a natural defence against future storms. The Conversation. Retrieved from theconversation.com/the -sydney-barrier-reef-engineering-a-natural-defenceagainst-future-storms-76862

Roggema, R. (2016). Research by design: Proposition for a methodological approach. Urban Science, 1(1), 2-20. http://dx.doi.org/10.3390/urbansci1010002

Roggema, R. (2012a). Swarm planning; The development of a methodology to deal with climate adaptation (Unpublished Doctorial dissertation). Delft University of Technology and Wageningen University and Research Centre, the Netherlands.

Roggema, R. (2012b). Swarming landscapes. In R. Roggema (Ed.), Swarming landscapes: The art of designing for climate adaptation (pp. 167-193). Dordrecht: Springer.

Roggema, R., \& Stremke, S. (2012). Networks as the driving force for climate design. In R. Roggema (Ed.), Swarming landscapes: The art of designing for climate adaptation (pp. 91-116). Dordrecht: Springer.

Roggema, R., \& Van den Dobbelsteen, A. (2012). Swarm planning for climate change: An alternative pathway for resilience. Journal for Building Research and Information, 40(5), 606-624.

Roggema, R., Van den Dobbelsteen, A., \& Stegenga, K. (2006). Pallet of possibilities (Report Spatial Team). Groningen: Grounds for Change.

Rossi-Hansberg, E. (2004). Cities under stress. Journal of Monetary Economics, 51, 903-927.

Sharmila, S., \& Walsh, K. J. E. (2018). Recent poleward shift of tropical cyclone formation linked to Hadley cell expansion. Nature Climate Change, 8, 730-736. http://dx.doi.org/10.1038/s41558-018-0227-5 
Stive, M. J. F., De Schipper, M. A., Luijendijk, A. P., Aarninkhof, S. G. J., Van Gelder-Maas, C., Van Thiel de Vries, ... Ranasinghe, R. (2013). A new alternative to saving our beaches from sea-level rise: The sand engine. Journal of Coastal Research, 29(5), 1001-1008. https://doi.org/10.2112/JCOASTRES-D-13-00070.1

Taleb, N. (2012). Antifragile. Things that gain from disorder. New York, NY: Random House.

Vermeer, M., \& Rahmstorf, S. (2009). Global sea level linked to global temperature. Proceedings of the National Academy of Sciences of the United States of America, 106(51), 21527-21532. https://doi.org/ 10.1073/pnas.0907765106

Walsh, J., Wuebbles, D., Hayhoe, K., Kossin, J., Kunkel,
K., Stephens, G., . . . Somerville, R. (2014). Our changing climate. In J. M. Melillo, T. C. Richmond, \& G. W. Yohe (Eds.), Climate change impacts in the United States: The third national climate assessment (pp. 19-67). Washington, DC: U.S. Global Change Research Program.

Wamsler, C., \& Brink, E. (2016). The urban domino effect: A conceptualization of cities' interconnectedness of risk. International Journal of Disaster Resilience in the Built Environment, 7(2), 80-113. https://doi.org/10.1108/IJDRBE-01-2015-0001

Weather.Gov. (n.d.). Introduction to storm surge. Weather.gov. Retrieved from www.weather.gov/ media/owlie/surge_intro.pdf

\section{About the Author}

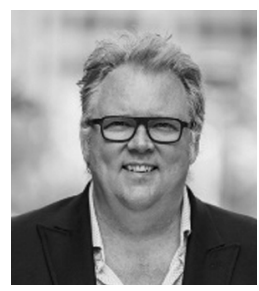

Rob Roggema $(\mathrm{PhD})$ is Professor of Sustainable Spatial Transformations at the Knowledge Centre Noorderruimte, Hanze University Groningen. He is a landscape architect and an internationally renowned design-expert on sustainable urbanism, climate adaptation, energy landscapes and urban agriculture. He has previously held positions at universities in the Netherlands and Australia, State and Municipal governments and design consultancies. Rob developed the Swarm Planning concept, a dynamic way of planning the city for future adaptation to the impacts of climate change. 